\title{
THE ROLE OF PRO-INFLAMMATORY NEUROPEPTIDES IN ULCERATIVE COLITIS
}

\author{
Pavlenko V. V., Alexandrova S. B., Tsurova E. A., Amirkhanova L. Z.
}

Stavropol State Medical University, Russian Federation

U lcerative colitis (UC) is a chronic recurrent disease, the pathogenesis of which involves complex interactions between genetic and environmental factors [3, 5, 6]. Mechanisms that trigger the first attack of UC and its relapses are not yet fully established. The recent scientific findings propose the regulatory role of the enteric nervous system (ENS) in the intestinal immune response and inflammatory response in the colon in UC $[7,8$, $13,16]$. ENS is the extended diffuse network of sensory neurons, interneurons, and motor neurons that control a variety of gastrointestinal functions. Involvement of nerve fibers in the pathophysiology of UC is confirmed by the fact that during the intestinal inflammation the nerve damage occurs in the colon, alongside with the disturbances in mucosa innervation and the abnormal expression of neuropeptides $[7,8$, $10,13,16]$.

It was shown that there is a link between the intestinal neuroendocrine system and the immune system which is due to the release of neuropeptides such as substance $P$ (SP) and neurotensin (NT), which belong to the family of intracellular signaling molecules [9, 10, 14, 17]. Neurons are the main source of neuropeptides, as well as the immune cells (lymphocytes, neutrophils, and macrophages), and enteroendocrine cells. Experimental and clinical data support the idea that SP and neurotensin regulate intestinal motor and secretory activity, increase capillary permeability, induce mast cell degranulation, affect immunoglobulin production and immune cells chemotaxis and phagocytosis, and neutrophil

Pavlenko Vladimir, MD, PhD, Professor, Head of the Department of internal diseases, Stavropol State Medical University; tel.: 89034451748; e-mail: PavlenkoVV@yandex.ru

Alexandrova Svetlana, Assistant of the Department of internal diseases propedeutics, Stavropol State Medical University; tel.: 89283027116; e-mail: AleksandrovaSB@yandex.ru

Zurova Elizaveta, Postgraduate student of the chair of propedeutics of internal diseases, Stavropol State Medical University; tel.: 89187492274; e-mail: LLLIZ04KA@RAMBLER.RU

Amirkhanova Leila, Cardiologist primary vascular Department MBUS № 3, Stavropol, applicant for the Department of propaedeutics of internal diseases, Stavropol State Medical University; tel.: 896244449026; e-mail: Leila-14@mail.ru lysosomal enzyme release, thus potentiating immunoinflammatory response in the colon $[7,10$, 11, 12, 14, 17].

Objective: to study the serum levels of proinflammatory neuropeptides substance $P$ and neurotensin in patients with ulcerative colitis.

Material and Methods. The study included 40 patients with active UC of varying severity (18 men and 22 women) aged 20-60 years during the treatment (in 6 weeks at the average). In 24 patients a recurrent form of UC was diagnosed, in 9 - a persistent one, and acute colitis was diagnosed in 7 patients. To determine the severity of UC Rahmilevich' activity index was used. Mild form of UC was found in 14 patients (clinical activity index $=1-5$ points), moderate form - in 20 patients (clinical activity index $=6-15$ points), and severe colitis was found in 6 patients (clinical activity index $=16-30$ points). Depending on the severity of the disease 5-ASA drugs, glucocorticosteroids (GCS), cytostatic agents, biological therapy (infliximab), and antibiotics were used, alongside with symptomatic therapy. The control group consisted of 15 healthy volunteers. SP and NT serum levels were determined by ELISA using standard test systems (Peptide Ensyme Immunoassay, Peninsula Laboratories, LLC, USA). Results were expressed in $\mathrm{ng} / \mathrm{ml}$.

SP serum levels in the control group were $0.004 \pm 0.01 \mathrm{ng} / \mathrm{ml}$, neurotensin serum levels equaled $0.682 \pm 0.19 \mathrm{ng} / \mathrm{ml}$.

Statistical analysis of the data was performed using the Student's t-test, Spearman's rank correlation test $\left(r_{\mathrm{s}}\right)$, and Fisher's exact test.

Results and Discussion. During the exacerbation of UC SP serum levels were found elevated $(0.583 \pm 0.07 \mathrm{ng} / \mathrm{ml}, \mathrm{P}<0.001)$, while the levels of NT were decreased $(0.023 \pm 0.009 \mathrm{ng} / \mathrm{ml}$, $\mathrm{P}<0.001$ ).

The issue of possible association between the serum levels of neuripeptides under consideration and the severity of CD was of particular interest.

As shown in Table 1, in patients with the persistent course of UC (Group 2) the comparative content of $\mathrm{SP}$ in the serum was the highest, while the serum levels of NT were the lowest. 
SP and NT serum levels in patients with UC as

UC as related to the course (form) of the disease $\left(\bar{X} \pm m_{X}\right)$

\begin{tabular}{|l|l|l|}
\hline \multirow{2}{*}{$\begin{array}{c}\text { Course (form) } \\
\text { of the disease }\end{array}$} & \multicolumn{1}{c|}{ Test characteristics } \\
\cline { 2 - 3 } & \multicolumn{1}{|c|}{ SP } & \multicolumn{1}{c|}{ NT } \\
\hline $\begin{array}{l}\text { 1st attack }- \text { the acute form } \\
(1)(n=7)\end{array}$ & $0.615 \pm 0.06^{*}$ & $0.074 \pm 0.003^{*}$ \\
\hline Persistent form (2) $(n=9)$ & $0.630 \pm 0.02^{*}$ & $0.084 \pm 0.004^{*}$ \\
\hline Recurrent form (3) $(n=24)$ & $0.530 \pm 0.07^{*}$ & $0.075 \pm 0.002^{*}$ \\
\hline$P_{1-2}$ & $P>0.05$ & $P<0.05$ \\
\hline$P_{1-3}$ & $P<0.001$ & $P>0.05$ \\
\hline$P_{2-3}$ & $P<0.001$ & $P<0.05$ \\
\hline
\end{tabular}

* $\mathrm{P}<0.001$ as compared with the control group data;

$\mathrm{P}_{1-2}$ - stands for the difference between the $1^{\text {st }}$ and $2^{\text {nd }}$ groups data;

$\mathrm{P}_{1-3}$ - stands for the difference between the $1^{\text {st }}$ and $3^{\text {rd }}$ groups data;

$\mathrm{P}_{2-3}$ - stands for the difference between the $2^{\text {nd }}$ and $3^{\text {rd }}$ groups data

The analysis of the parameters under the study was held in patients with varying severity of the UC (Table 2).

Table 2

SP and NT serum levels in patients with UC as related to the activity of the disease $\left(\bar{X} \pm m_{\bar{X}}\right)$

\begin{tabular}{|l|c|c|}
\hline \multirow{2}{*}{ Activity of the UC } & \multicolumn{2}{|c|}{ Test characteristics } \\
\cline { 2 - 3 } & SP & NT \\
\hline Mild $(1)(n=11)$ & $0.510 \pm 0.08^{*}$ & $0.07 \pm 0.004^{*}$ \\
\hline Moderate $(2)(n=23)$ & $0.590 \pm 0.06^{*}$ & $0.025 \pm 0.009^{*}$ \\
\hline Severe $(3)(n=6)$ & $0.629 \pm 0.03^{*}$ & $0.022 \pm 0.01^{*}$ \\
\hline$P_{1-2}$ & $P<0.05$ & $P<0.05$ \\
\hline$P_{1-3}$ & $P<0.05$ & $P<0.001$ \\
\hline$P_{2-3}$ & $P<0.05$ & $P>0.05$ \\
\hline
\end{tabular}

* $\mathrm{P}<0.001$ as compared with the control group data;

$\mathrm{P}_{1-2}$ - stands for the difference between the $1^{\text {st }}$ and $2^{\text {nd }}$ groups data;

$\mathrm{P}_{1-3}$ - stands for the difference between the $1^{\text {st }}$ and $3^{\text {rd }}$ groups data;

$\mathrm{P}_{2-3}$ - stands for the difference between the $2^{\text {nd }}$ and $3^{\text {rd }}$ groups data

It was found that during the period of acute clinical presentations of the UC the SP serum levels correlated directly with the severity degree of the UC, whilst the NT serum content demonstrated the inverse correlation.

In the same way, a direct significant correlation was established between clinical activity index of UC and SP serum levels, and the reverse one in relation to the NT serum levels.

On the onset of clinical remission in the course of the treatment (in 6 weeks at the average) SP serum levels were found decreased $(0.034 \pm 0.01 \mathrm{ng} / \mathrm{ml}$, $p<0.001$ when compared with the acute phase data), but they didn't reach the control values $(p<0.05)$. In the same period there was an increase in the NT serum content $(0.385 \pm 0.08 \mathrm{ng} / \mathrm{ml}, \mathrm{p}<0.001$ when compared with the acute stage data), although it didn't come up to the control values either.

To study the impact of pharmacological agents and their combinations used in UC therapy on the content of proinflammatory neuropeptides being discussed the patients were stratified into several treatment groups.

In the first group there were 11 patients with mild UC treated with 5-aminosalicylic acid drugs (5-ASA) as a monotherapy. The second group consisted of 21 patients with moderate UC receiving a combination of 5-ASA drugs with corticosteroids (prednisone, budesonide). The third group consisted of 5 patients with severe UC who received combination therapy with hormones and azathioprine in the recommended doses. In the fourth group there were 4 patients with a high degree of UC clinical activity, treated with Infliximab (Remicade) (induction scheme, $5 \mathrm{mg} / \mathrm{kg}$ ) in addition to the basic treatment of the desease.

All the drugs used in UC therapy were shown to influence positively on the content of the studied neuropeptides in the peripheral blood (Figure). Thus, the UC clinical remission onset was accompanied by the decrease in the SP serum levels and the increase in the NT serum levels, irrespective of the combination of the drugs used. At the same time in a group of patients with severe UC that was refractory to the conventional basic therapy, a three-fold intravenous Remicade (Infliximab) administration resulted in normalization of the neuropeptides' levels on the 6th week of treatment already.

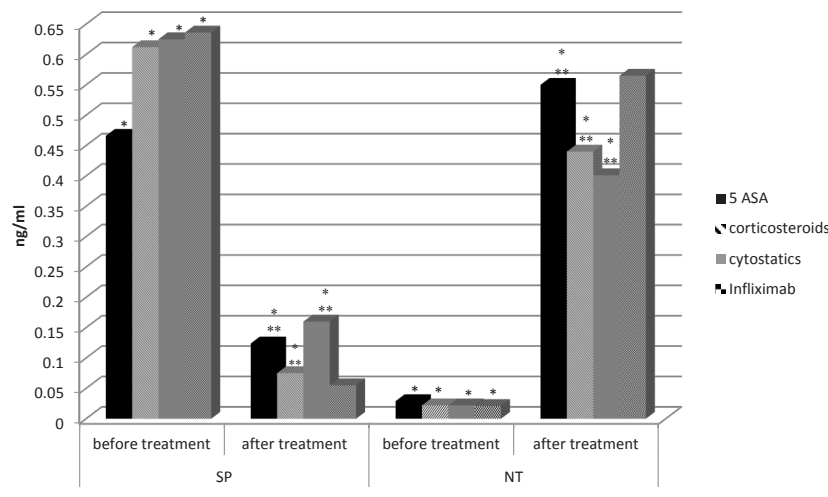

${ }^{\star} \mathrm{P}<0.05$ as compared with the control group data;

${ }^{\star *} \mathrm{P}<0.05$ between the groups before and after therapy.

Fig. Progression of the SP and NT content in blood serum as related to the drugs used in the treatment of the UC

The established regularities in the content of substance $P$ and neurotensin in the peripheral blood of patients with different clinical forms of UC confirm their involvement into the pathophysiological processes in the colon.

It is known that substance $P$ is released in response to the damage of colonic mucosa $[9,10$, $11,12,14,17]$. The in vitro studies revealed the stimulating effect of substance $P$ on the reactivity of monocytes / macrophages, lymphocytes, eosinophils, neutrophils, and mast cells [7, 13, 14, 17]. The proinflammatory activity of substance $P$ and neurotensin was validated in vivo using several experimental models of colitis. In rodent enterocolitis induced by toxin A (Clostridium difficile), a specific substance P antagonist CP-96.345 blocked the SP NK-1 receptors thus significantly reducing the toxin 
A caused secretion of chlorides and fluid in the gut, at the same time suppressing the inflammation process and the mucosal damage $[13,15,17,18]$. Neurotensin demonstrated the ability to activate several types of immune and inflammatory cells through interaction with $\mathrm{R} 1$-receptors (i. e. degranulation of mast cells in the small and large intestine; transportation, phagocytosis and adhesion of neutrophils and Iymphocytes; IL-1 $\beta$ and PGE $_{2}$ production), thus modulating the intestinal inflammation $[9,10,14]$.

The beneficial impact demonstrated by the drugs used in the treatment of various forms of UC is due to their direct or indirect effect on the different inflammatory cascades. As a result of 6 weeks' treatment with different groups of basic drugs the levels of neuropeptides studied were found decreased, although they were higher than the control values. Thus, the 5-ASA drugs modulate immune responses by blocking the release of inflammatory mediators $[3,5,6]$. Pathogenic justification for the use of GCS in UC is based on their cellular effects, i. e. modulation of leukocytes and lymphocytes recruitment, reduced leukocyte adhesion and chemotaxis, phagocytosis suppression, decreased adhesion molecules expression, suppressed production of antibodies, the inhibition of cell-mediated cytotoxicity and release of inflammatory mediators. Furthermore, steroids reduce neuronal loss in the myenteric plexus, thereby restoring the affected innervation in the colonic mucosa and expression of neuropeptides [3, 4, 5, $6]$. Azathioprine, being a structural analogue of an adenine, hypoxanthine, and guanine which are the components of the nucleic acids, blocks cell division and proliferation of tissues. Immunosuppressive effect of azathioprine is directed mainly on the reaction of delayed hypersensitivity and cellular cytotoxicity.

The administration of biological therapy in patients with resistant forms of $U C$ resulted in normalization of the levels of substance $P$ and neurotensin in the blood on the onset of UC clinical remission. The mecha-

\section{References}

1. Bakulin I. G., Stanke D. A., Belousova E. A., Mikhailova T. L. Activity Indices pose objective criteria for assessing the severity of ulcerative colitis. Experimental Clinical Gastroenterology. 2008;6:14-16.

2. Beloborodova E. I., Burkovskaya V. A., Markidonova A. A. et al. Assessment of the severity of ulcerative colitis. Siberian Medical Journal. 2012:3:136-138.

3. Khaliph I. L., Loranskaya I. D. Inflammatory bowel disease (Ulcerative colitis and Crohn's disease): The clinical findings, diagnosis and treatment. M.: «Miklosh»; 2004. 88 p.

4. Galeeva Z. M. Modern aspects of treatment for ulcerative colitis in terms of evidence-based medicine. Bulletin of modern clinical medicine. 2010;2(3):47-50.

5. Gastroenterology: national guidelines / ed. V. T. Ivashkina, T. L. Lapina. M.: «GEOTAR Media»; 2008. 704 p.

6. Nonspecific inflammatory bowel disease / ed. G. I. Vorobyev, I. L. Khalif. M.: «Miklosh»; 2008.400 p.

7. Komarov F. I., Osadchuk A. M., Osadchuk M. A., Kvetnoy I. M. Ulcerative colitis. Moscow: «Medical Information Agency»; 2008. 256 p.

8. Brun P., Mastrotto C., Beggiao E. et al. Neuropeptide neurotensin stimulates intestinal wound healing following chronic intestinal inflammation. J. Am. Physiol. Gastrointest. Liver Physiol. 2005;288:621-629.

9. Neunlist M. et al. Changes in chemical coding of mysenteric neurones in ulcerative colitis. Gut. 2003;52:84-90.

10. Fiebich B. L., Schleicher S. et al. The neuropeptide substance $\mathrm{P}$ activates p38 mitogen-activated protein kinase resulting in IL-6 expression independently from NF-kappa B. J. Immunol. 2000;165:5606-5611. nisms underlying the inhibitory property of TNF- $\alpha$ related to the pro-inflammatory neuropeptides are currently being studied. It is known that TNF- $\alpha$ activates the SP synthesis in the sympathetic ganglia through the sequential induction of interleukin-1 and leukemia inhibitory factor. At the same time, the SP may directly enhance the proinflammatory responses in target cells, including the secretion of IL-1 $\beta, \mathrm{IL}-6$, and potent chemoattractants IL- 8 and TNF- $\alpha[3,4,6]$. Infliximab demonstrates high affinity for TNF- $\alpha$, binds to readily and forms a stable compounds with both of its two forms (soluble and transmembrane), thus reducing its functional activity and suppressing the inflammatory response in the gut $[3,4,6]$.

We believe that the study of the neurotransmitters content in UC may be essential to the duly assessment of the immunopathological process activity, alongside with the prediction of the treatment efficacy, and creates opportunities for the new therapeutic targets search.

\section{Conclusion}

1. During the exacerbation of UC the SP serum levels were increased, while there was a decrease in neurotensin serum levels.

2. In patients with the persistent form of the UC the substance $P$ serum levels were the highest, while the serum levels of neurotensin were found to be the lowest.

3. SP serum levels were in direct correlation with the severity of UC, and the NT serum levels demonstrated inverse correlation.

4. A direct correlation was found between the clinical activity index rates and SP serum levels, and a reverse one for the NT serum levels.

5. The onset of clinical remission of UC is accompanied by a decrease in SP content and increased serum levels of NT.

6. Progression of the neuropeptides content is dependent on the drugs used in the treatment of the UC.

11. Gandhu M. V. Visceral pain perception is determined by the duration of colitis and associated neuropeptide expression in mice. Gut. 2007;56:358-364.

12. Kara J., Gross M. D., Charalabos Pothoulakis M. D. Role of Neuropeptides in Inflammatory Bowel Disease. Inflammatory Bowel Diseases. 2007;13:918-932.

13. Karagiannides I. Induction of colitis causes inflammatory responses in fat depots: evidence for substance $P$ pathways in human mesenteric preadipocytes. Proc. Natl. Acad. Sci. USA. 2006;103:5207-5212.

14. Koon H. W., Pothoulakis C. Immunomodulatory Properties of Substance P. The Gastrointestinal System as a Model. N.Y. Ann. Acad. Sci. 2006;1088:23-40.

15. Riddell R. H., Kirsner J. B. Pathology of idiopathic inflammatory bowel disease. Inflammatory Bowel Disease. W.B. Saunders company, Philadelphia; 2000. P. $427-450$.

16. Ter Beek W. P., Biemond I. et al. Substance $P$ receptor expression in patients with inflammatory bowel disease. Determination by three different techniques, storage phosphor autoradiography, RT-PCR and immunohistochemistry. Neuropeptides. 2007;41:301306.

17. Hansen M. B. The Enteric Nervous System III: F Target for Pharmacological Treatment. Pharmacology \& Toxicology. 2003:93:1-13.

18. Wehkamp J., Fellermann K., Herrlinger K. R. et al. Mechanisms of disease: defensins in gastrointestinal diseases. Nat. Clin. Pract. Gastroenterol. Hepatol. 2005;2:406-415. 
THE ROLE OF PRO-INFLAMMATORY

NEUROPEPTIDES IN ULCERATIVE COLITIS

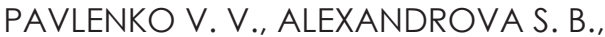

TSUROVA E. A., AMIRKHANOVA L. Z.

The study included 40 patients with ulcerative colitis during the treatment with various drug combinations. Serum levels of neuropeptides were measured with ELISA assay.

It was found that during the exacerbation of ulcerative colitis the substance P (SP) is increased in serum, while there is a decrease in neurotensin serum levels. SP serum levels were in direct correlation with the severity of the disease under discussion, and the NT serum levels demonstrated inverse correlation.

Drugs used in the treatment schemes for ulcerative colitis are able to modulate the serum levels of neuropeptides under consideration in patients with active ulcerative colitis.

Key words: ulcerative colitis, neuropeptides

\section{РОАЬ ПРОВОСПААИТЕАЬНЫХ}

НЕЙРОПЕПТИАОВ ПРИ ЯЗВЕННОМ КОАИТЕ

В. В. ПАВАEHKO, С. Б. A^ЕКСАHАPOBA,

Е. А. ЦУРОВА, ^. 3. АМИРХАНОВА

Обследованы 40 пациентов с язвенным колитом в динамике лечения различными комбинациями лекарственных препаратов. Содержание нейропептидов в сыворотке крови определяли методом иммуноферментного анализа.

Установлено, что в период обострения язвенного колита содержание вещества Р в сыворотке крови повышено, а уровень нейротензина снижен. Содержание SP в сыворотке крови находилось в прямой зависимости от тяжести заболевания, а уровень NT - в обратной.

Используемые в терапии язвенного колита лекарственные препараты способны модулировать уровень изучаемых нейропептидов в сыворотке крови больных активным язвенным колитом.

Ключевые слова: язвенный колит, нейропептиды

\title{
INTRACELLULAR ADHESION MOLECULES AND HISTOLOGICAL PATTERN IN CHRONIC VIRAL LIVER DISEASES
}

\author{
Koroy P. V., Mukhoramova I. S., Yagoda A. V.
}

\section{Stavropol State Medical University, Russian Federation}

AN imbalance between fibrogenesis and fibrolysis that develops as a result of excessive production of extracellular matrix molecules, reduced expression of tissue metalloproteinases, and an increase in their inhibitors' synthesis in stellate cells leads to hepatic fibrosis $[7,19]$, and, in case of its progression - to hepatic cirrhosis, disruption of the relationship between the hepatocytes metabolism and the hepatic vascular bed [15].

Given the crucial role of the endothelium in the development of inflammatory and immune responses, the link between intracellular adhesion molecules and morphological changes in the liver appears a logic one. Leukocytes and sinusoidal cells interactions are involved into the pathogenesis of acute liver damage, while the immuno-

Koroy Pavel, MD, PhD, Professor, Department of Hospital Therapy, Stavropol State Medical University tel.: 9282938068, e-mail: paule75@yandex.ru

Mukhoramova Irina, MD, Gastroenterology Department, Stavropol Regional Centre for Specialized Medical Assistance; tel.: 9054484141

Yagoda Alexander, MD, PhD, Professor, Head

of Department of Hospital Therapy, Stavropol State Medical University; tel.: 89064907330, e-mail: alexander.yagoda@gmail.com globulin superfamily plays a key role in the noted intracellular reactions $[13,21]$. Thus, in the model of endotoxin-induced liver injury, an increase in the expression of the intercellular adhesion molecule type 1 (ICAM-1) and the vascular cell adhesion molecule type 1 (VCAM-1) in sinusoidal cells caused increased neutrophil infiltration in liver sinusoids, whereas concanavalin-induced hepatitis taken against the ICAM-1 deficiency, on the contrary, could be characterized with the minimal evidence of liver necrosis and low aminotransferase activity [8]. There has been positive correlation noticed for TNF- $\alpha$ mRNA expression in liver with tissue expression of ICAM-1 and VCAM-1 mRNAs in patients with hepatic cirrhosis [12].

In case of moderate and severe morphological signs of chronic viral hepatitis $(\mathrm{CVH})$, there are relatively higher plasma and tissue concentrations of ICAM-1 and VCAM-1 [1, 5, 20], which were in positive correlation with the histological activity index $[1,3,5,6]$. A progression of hepatic fibrosis against the $\mathrm{HCV}$ infection was associated with a significant increase in ICAM-1 and VCAM-1 blood concentrations and direct relationship of the mediators' profiles with the hepatitis stage $[2,5,6]$. There is also an opposite viewpoint available, which 